\title{
Measuring Selected Parameters of Polypropylene Fibre Heat Exchangers
}

\author{
Mária Čarnogurská1, ${ }^{*}$ - Miroslav Př́ihoda ${ }^{2}$ - Marián Lázár ${ }^{-}$ \\ Natália Jasminská ${ }^{1}$ - Róbert Gallik ${ }^{1}$ - Michal Kubík ${ }^{1}$ \\ ${ }^{1}$ Technical University of Košice, Faculty of Mechanical Engineering, Slovakia \\ ${ }^{2}$ Technical University of Ostrava, Faculty of Metallurgy and Materials Engineering, Czech Republic
}

Heat exchangers whose heat exchange surfaces are made of the miniature polypropylene fibres are still under development. In the first phase of researching such exchangers, the possibility of attaching fibres into bundles was tested. The number of threads in one bundle ranges from several hundred to thousands of pieces. The sensitive element in the application of the fibres in a heat exchanger is the place where all the fibres are bundled together, into so-called potting, which must be perfectly tight. Pressure loss was measured in such bundles, depending on the water flow and the temperature at the entry and exit of the exchanger. The results allowed the definition of the overall heat transfer coefficient from one medium through the fibre wall to the other media and to determine the thermal performance of the exchanger. Experimental data shows that water-to-water heat exchanger reached the overall heat transfer coefficient value of to $800 \mathrm{~W} \cdot \mathrm{m}^{-2} \cdot \mathrm{K}-1$, depending on the release rate of the bundle. Subsequently, for the given conditions, the heat transfer rate depends only on the size of the heat transfer surface area, thus the number of fibres in the bundle.

Keywords: polypropylene fibre, heat exchanger, measurement

Highlights

- A new type of heat exchanger whose heat exchange surface consists of polypropylene fibres has been designed and tested.

- A testing seal potting apparatus has been developed.

- Media temperature, flow rate and pressure drop in selected bundles of fibres with transparent and porous fibre were measured.

- The impact of fibre length on the value of the overall heat transfer coefficient for this new type of heat exchanger was examined.

\section{INTRODUCTION}

Currently, the proposed design of heat exchangers and other equipment must satisfy complex requirements in terms of production technology [1] and [2], troublefree operation [3] and economic feasibility [4] and [5]. The main requirements for heat exchangers include a large overall heat transfer coefficient, low flow resistance, a simple process of cleaning the heat transfer surface area, corrosion resistance in various transported media, adaptation of the shape of the heat exchanger to the specified manufacturing needs, as well as price [6] and [7].

The critical operating parameters being monitored in heat exchangers include [8] and [9]:

- Operating pressure: that can range from a deep vacuum in fractions of $\mathrm{Pa}$ to pressures reaching tens of MPa.

- Operating temperature: from values close to absolute zero up to $1000^{\circ} \mathrm{C}$ and higher.

- Mass flow rate: from a few grams to hundreds of kilograms of media per second.

- Good accessibility to a heat exchange area (necessary condition for cleaning and checking the status of working surfaces, especially when working with corrosive chemicals or a heterogeneous suspension with a tendency to form deposits, encrustations and corrosion).

Decontamination and hygiene of a heat exchange surface is a specific condition for heat exchangers in the area of food and medical technologies. In addition to physical and chemical cleanliness, decontamination requirements also include bacterial cleanliness and harmlessness of heat exchange surfaces.

In industrial practice, the most often used heat exchangers are constructed of steel or other metals; plastic is used less commonly as a construction material.

As for plastic heat exchangers, the advantage is the durability of the material (up to 50 years), resistance to corrosion, chemicals and bacteria, high sanitary standards and low volume weight.

One of the disadvantages of plastic heat exchangers is their lower material strength in comparison to metal exchangers, low resistance to higher temperatures $\left(\max .150{ }^{\circ} \mathrm{C}\right)$, lower resistance to mechanical damage, risk of penetration of the diffused oxygen into the cooling medium, as well as a lower connection quality [10] and [11]. 
Individual parts of a heat exchanger are connected by glue or are welded. Welded constructions of heat exchangers are of a better quality and also find application in highly aggressive environments.

A particular feature of plastic heat exchangers is that they are not produced in a gilled configuration because of the low thermal conductivity of the plastic.

A separate group of plastic heat exchangers are heat exchangers in which the heat exchange surface is made of polypropylene fibres (capillaries) [12] and [13].

Other cited works state the results of experiments by individual authors related to, for example, the possibility of using heat exchangers with polypropylene fibres to obtain waste heat from domestic and industrial water was assessed [14] and [15], the studies of the affinity of polypropylene fibres for biological pollution in comparison with stainless steel (Escherichia coli bacteria) [16], the use of exchangers with polypropylene fibres (as a source of heat) for thermal pumps was investigated [17], the interaction between the movement of fibres and heat transfer was monitored, the impact of the shape and size of the heat exchanging area upon the output of the exchanger was assessed the use of exchangers with polypropylene fibres (as a source of heat) for thermal pumps was investigated [18] and [19], etc.

The geometry of polypropylene fibres is shown in Fig. 1.

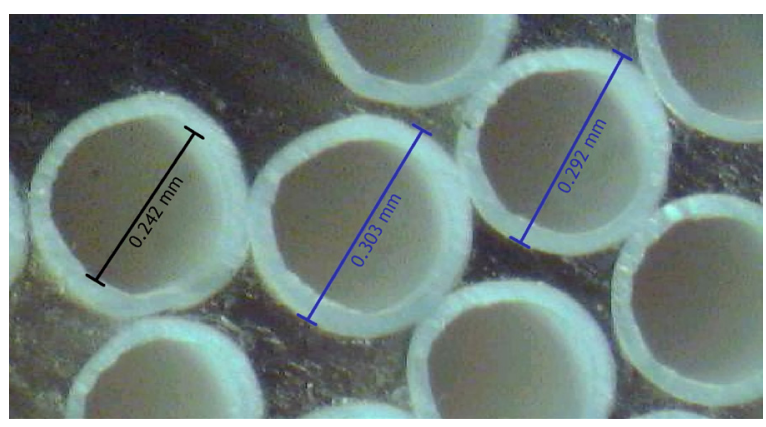

Fig. 1. The polypropylene fibres - $200 \times$ magnifications

Table 1. Basic physical characteristics of propylene [21]

\begin{tabular}{lc}
\hline Measured parameter & Value \\
\hline Density $\left[\mathrm{g} \cdot \mathrm{cm}^{-3}\right]$ & 0.95 (crystal) \\
\cline { 2 - 2 } & 0.895 (amorphous) \\
\hline Melting point $\left[{ }^{\circ} \mathrm{C}\right]$ & 173 \\
\hline Decomposition point $\left[{ }^{\circ} \mathrm{C}\right]$ & 286 \\
\hline Thermal expansion $\left[\mathrm{K}^{-1}\right]$ & $(100$ to 180$) \cdot 10^{-6}$ \\
\hline Specific thermal capacity $\left[\mathrm{kJ}^{-} \cdot \mathrm{kg}^{-1} \cdot \mathrm{K}-1\right]$ & 1.70 to 1.90 \\
\hline Water absorption $[\%]$ & 0.03 \\
\hline Hardness [Rockwell] & $\mathrm{R} 80$ to $\mathrm{R} 100$ \\
\hline Thermal conductivity $\left[\mathrm{W} \cdot \mathrm{m}^{-1} \cdot \mathrm{K}^{-1}\right]$ & 0.16 to 0.25 \\
\hline
\end{tabular}

Polypropylene is a thermoplastic polymer selected from the group of polyolefins; it is colourless and odourless [20] and [21]. It has good stability, hardness and strength, but low impact strength. It is not susceptible to internal stress and can be appropriately welded. It has excellent electrical and chemical resistance. It becomes fragile at temperatures below zero. The basic physical properties of polypropylene are shown in Table 1.

\section{STUDY AREA}

In the first phase of designing a heat exchanger surface made of polypropylene fibres, research was carried out to see if there was the possibility of joining polypropylene fibres into bundles. A created bundle (Fig. 2) consists of 1400 pieces of fibre. Those fibres are inserted into a $20 \mathrm{~mm}$ diameter and $40 \mathrm{~mm}$ long PVC tube. The part of the fibres that is glued into a single unit, and forms a compact unit in a PVC tube, is the so-called potting. Fig. 3 shows a sectional view of an array of 18 pottings in a single shell of a heat exchanger. The manner in which the bundles are placed, and especially by their number, makes it possible to influence the thermal performance of the heat exchanger.

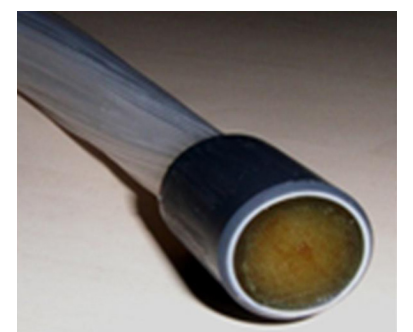

Fig. 2. Fibre bundle in a potting

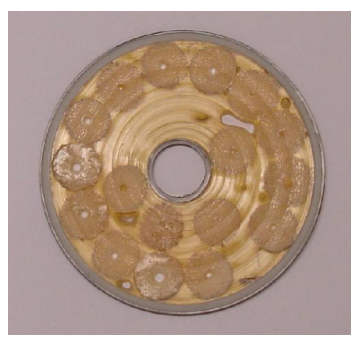

Fig. 3. System of pottings side cut
The fibres are produced by continuous casting of liquid polypropylene from an extruder. Subsequently, the fibre is cooled in an air stream, thereby shrinking into the given dimension. Fibres suitable for the use in a heat exchanger should have intact and smooth walls, i.e. so-called transparent fibres. In contrast, research is underway to examine the possibility of using a porous fibre mainly for medical purposes. The wall of such fibres consists of $30 \%$ to $50 \%$ air.

The second phase of the design tested the potting leaks. Table 2 contains the selected technical parameters of a bundle of polypropylene fibres.

The bundle is tested for the so-called collapse pressure and burst pressure. Collapse pressure is an overpressure from the outside of the fibre wall 
towards the inside wall, following which the fibre wall collapses. Burst pressure indicates the overpressure inside of the capillary against the external pressure, following which there is a rupture of the capillary wall.

Table 2. Technical parameters of a polypropylene fibre bundle

\begin{tabular}{lc}
\hline Parameter & Value \\
\hline Capillary material & Polypropylene \\
\hline Potting material & Polyurethane \\
\hline Number of capillarie & 1400 \\
\hline Total length & $750 \mathrm{~mm}$ \\
\hline Capillaries inner diameter & $0.225 \mathrm{~mm}$ \\
\hline Outer diameter of capillaries & $0.275 \mathrm{~mm}$ \\
\hline Collapse pressure & $0.2 \mathrm{MPa}$ \\
\hline Burst pressure & $0.4 \mathrm{MPa}$ \\
\hline Maximal operating temperature & $70{ }^{\circ} \mathrm{C}$ \\
\hline Approx. heat transfer area & $1 \mathrm{~m}^{2}$ \\
\hline
\end{tabular}

\section{CHARACTERISTICS OF POLYPROPYLENE FIBRES}

Polypropylene fibres can deform or even break when cut, or after being glued in the potting. A rupture occurs when the adhesive does not completely fill the empty space between the fibres. A rupture is a permanent deformation of the fibre cross-section, i.e. reduced cross-section (Fig. 4).

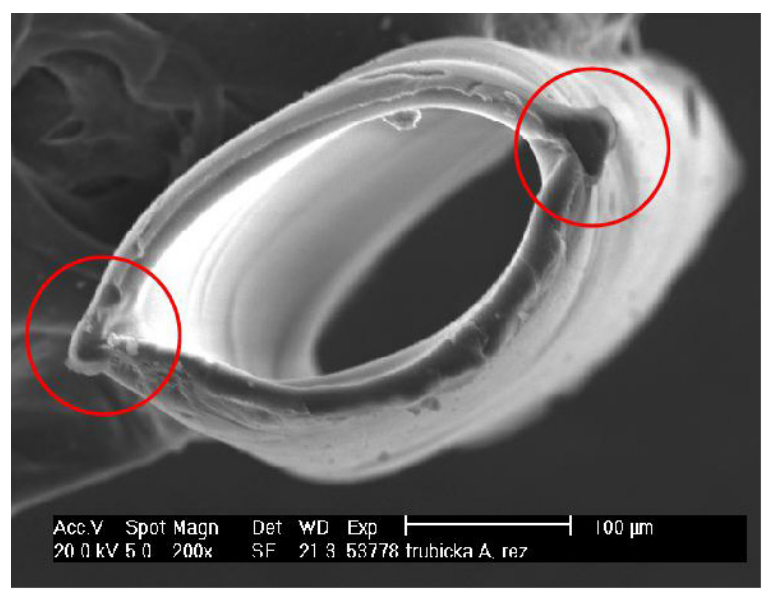

Fig. 4. Polypropylene fibre cut- $200 \times$ magnification

Wall thickness changes along the length of an intact fibre. Fig. 5 shows a microsection of the wall at $1500 \times$ magnification. The changing of the wall thickness is chaotic; it is not subject to any dependency, not only along the cross-section but also along the length of the capillary. The wall thickness of the presented capillary ranges from $30 \mu \mathrm{m}$ to $33 \mu \mathrm{m}$.

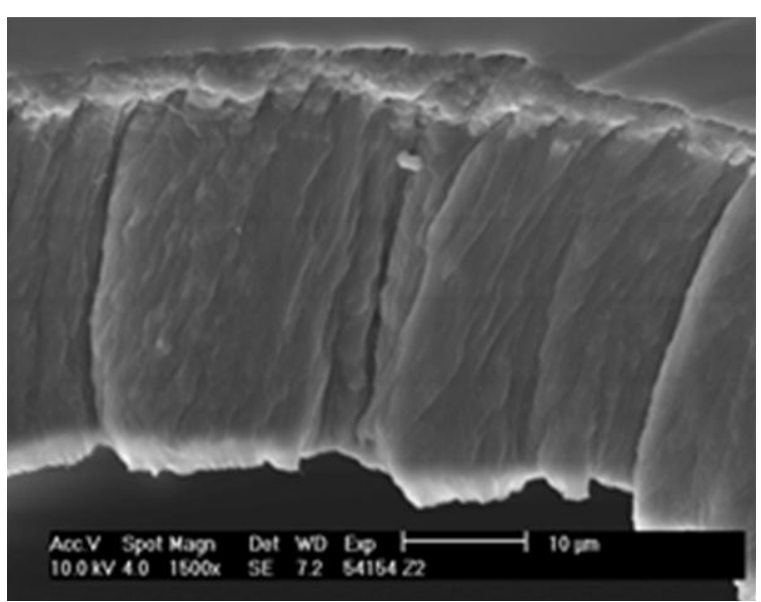

Fig. 5. Microsection of the wall along the length of the fibre $1500 \times$ magnification

\section{TESTING POTTING INTEGRITY}

As a potting is made of three different materials with differing properties, it was necessary to conduct an integrity test. The test device is shown in Fig. 6.

Water coming from a pressurized water source passes through a water filter (1), continues through a closing valve (2) and after the control pressure gauge (3) it enters the first potting. The water flows through the fibre bundle and enters the second potting (5). Subsequently, the water flows through the control pressure gauge (6) and the closing valve (7), which flows into a collecting tank. The water pressure at the inlet of the water filter was set to $0.3 \mathrm{MPa}$. Water flowing under this pressure for $30 \mathrm{~s}$ expelled the air contained in the fibres of the bundle. Subsequently, the valves were closed before and after the bundle; the pressure drop in the fibre bundle was observed for $5 \mathrm{~min}$.

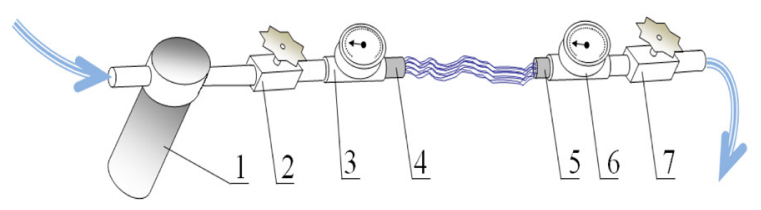

Fig. 6. Scheme of a potting's' integrity measurement

This particular experiment was conducted in order to identify a possible problem with the tightness of the bundle. A fibre bundle with detected leakage was immersed into a water tank at $50{ }^{\circ} \mathrm{C}$ to $70{ }^{\circ} \mathrm{C}$ together with a protective package perforated with about 30 holes, $3 \mathrm{~mm}$ in diameter. The packaging was tasked to protect fibres from mechanical damage during the repeat experiment. After cooling the fibre to the level of the inlet temperature, the fibre bundle 
was again exposed to a water pressure of $0.3 \mathrm{MPa}$. The potting was tested in this manner over several cycles. The number of cycles at the time of individual testing increased with the increasing success of previous pressure tests. Table 3 shows the results of the tested fibre bundle.

The same procedure was used for testing the tightness of the pottings at a high water temperature in a water bath into which the bundle was immersed after the test. The results showed that the potting's exhibited leakage at a temperature above $52^{\circ} \mathrm{C}$.

\section{MEASUREMENT OF PRESSURE LOSS FIBRE BUNDLES}

The pressure drop was measured on six selected fibre bundles. Three fibre bundles consisted of transparent fibres and the other three with porous ones. Potting tightness before the measurement was $100 \%$. All parameters of the tested bundles (outer diameter, number of fibres in a bundle, and their length) were identical. A source of the pressurized water was represented by a pressurized water supply network with a pressure of $0.45 \mathrm{MPa}$ and a temperature of $18{ }^{\circ} \mathrm{C}$. The fibre bundle was connected to the rubber hoses via an inlet (4) and an output potting (5) (Fig. 7).

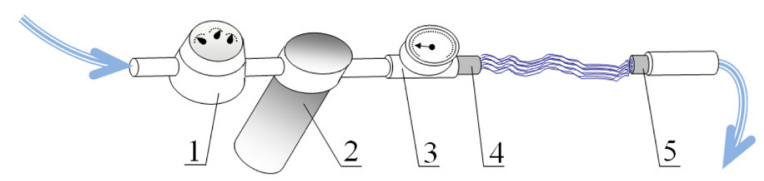

Fig. 7. Schematic diagram of a fibre bundle during the measurement of a pressure loss

The water flowed into the bundle through a flow metre (1) and a water filter (2). Water pressure was measured with a type PM 03.05 pressure gauge (3), with an amplitude between $0 \mathrm{MPa}$ and $0.6 \mathrm{MPa}$ and with an accuracy of $\pm 0.3 \%$. Fig. 8 shows the dependency of the pressure loss and water flow through the fibre bundle. The bundles of transparent fibres ( $\mathrm{t} 1$ to $\mathrm{t} 3$ ) and bundles of porous fibres ( $\mathrm{p} 1$ to $\mathrm{p} 3$ ) show an almost linear progression of the change in a pressure drop in the flow rate.

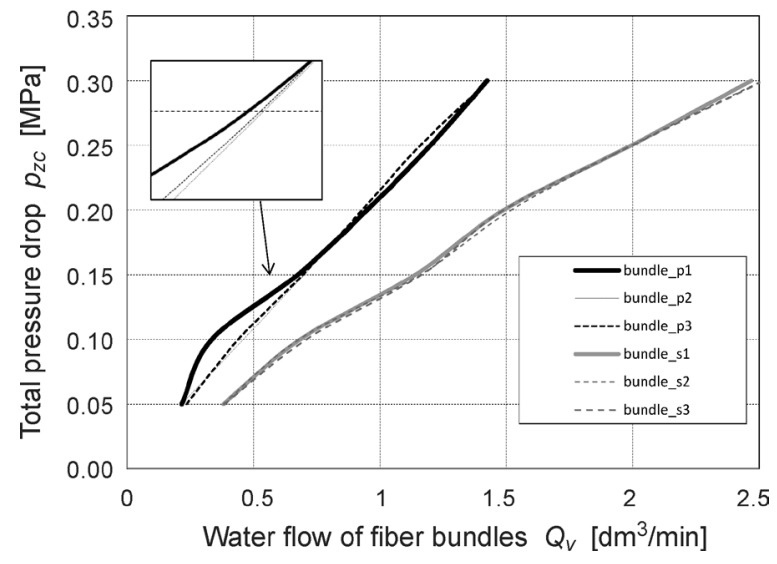

Fig. 8. Pressure drop fibre

\section{MEASUREMENT OF TEMPERATURE AND FLOW}

An experiment with an integrated bundle of transparent polypropylene capillaries was conducted on a heat exchanger that was constructed in a countercurrent wiring with a tangential inlet of the secondary medium (Fig. 9).

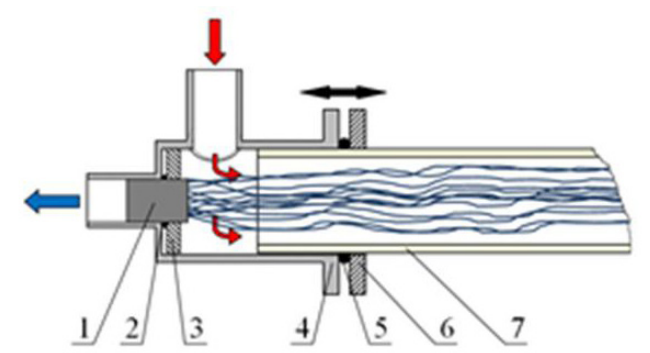

Fig. 9. Heat exchanger with a tangential inlet and sliding head

Table 3. Integrity test - measurements results

\begin{tabular}{cccccccc}
\hline test number & $\begin{array}{c}\text { Interval between } \\
\text { individual tests }[\mathrm{h}]\end{array}$ & $Q_{V}\left[\mathrm{dm}^{\left.3 \cdot \mathrm{min}^{-1}\right]}\right.$ & $p[\mathrm{MPa}]$ & $t_{i}\left[{ }^{\circ} \mathrm{C}\right]$ & $l[\mathrm{~m}]$ & $n_{c}[\mathrm{l}]$ & $t_{w}\left[^{\circ} \mathrm{C}\right]$ \\
\hline basic test & - & 1.61 & 0.3 & 19.2 & 0.726 & - & - \\
\hline 2 & 18 & 1.61 & 0.3 & 19.1 & 0.724 & 3 & 52 \\
\hline 3 & 15 & 1.58 & 0.3 & 18.8 & 0.722 & 13 & 52 \\
\hline 4 & 151 & 1.63 & 0.3 & 18.3 & 0.720 & 13 & 52 \\
\hline 5 & 151 & 1.66 & 0.3 & 18.1 & 0.716 & 18 & 52 \\
\hline
\end{tabular}

Note: $n_{c}$ the number of reheating cycles of the bundle and its subsequent re-cooling down, $l$ bundle length, $p$ pressure of water in the fibres during the test, $t_{i}$ temperature of the test water in the capillaries before the test, $t_{w}$ the temperature of the water in which the bundle was submerged. 
The construction of the shell of heat exchanger allowed the release of fibres in a range from $0 \%$ to $10 \%$. The exchanger has been studied for the impact of the fibres' tension on the intensity of the heat transport. A sliding head (4) placed on the shell of the heat exchanger (7) together with a rubber seal (5) and a thrustwasher (6) were used for this purpose. The potting of the investigated bundle itself (1) was sealed using a so-called O-ring (2) and pressed with a washer (3).

The experiment used three different versions of a fibre bundle. Each version had a different number of fibres, different outer fibre diameter and a variety of tensions. The parameters of the heat exchangers are shown in Table 4.

At zero tension, the fibre is at $100 \%$ of its length, and the fibre axis is a straight line. When released, the bundle changes the distance between the clamping of the pottings; the fibre length remains constant. The bundle release $\Delta l_{u}[\%]$, expressed as a percentage of the total length of the fibres, is described by Eq. (1):

$$
\Delta l_{u}=100-\frac{\left(l_{z}-\Delta_{l}\right) \cdot 100}{l_{z}} .
$$

Given the diameter and the size of fibres, the release of individual bundles was chosen as per Table 5.

View of the experimental stand is shown in Fig. 10.

Table 4. Parameters of used bundles

\begin{tabular}{ccccc}
\hline $\begin{array}{c}\text { Type of } \\
\text { a bundle }\end{array}$ & $\begin{array}{c}\text { Number of } \\
\text { fibres [pc] }\end{array}$ & $\begin{array}{c}\text { Outer diameter } \\
{[\mathrm{mm}]}\end{array}$ & $\begin{array}{c}\text { Fibre length } \\
{[\mathrm{m}]}\end{array}$ & $\begin{array}{c}\text { Heat transfer } \\
\text { area [m²] }\end{array}$ \\
\hline A & 400 & 0.65 & 0.71 & 0.580 \\
\hline B & 900 & 0.35 & 0.70 & 0.682 \\
\hline C & 1385 & 0.275 & 0.70 & 0.834 \\
\hline
\end{tabular}

Table 5. Release values for different types of bundles

\begin{tabular}{cccc}
\hline Type of a bundle & \multicolumn{3}{c}{$\Delta l_{u}[\%]$} \\
\hline A & 0 & 0.7 & 1.4 \\
\hline B & 0 & 1.5 & 3 \\
\hline C & 0 & 1.4 & 3.7 \\
\hline
\end{tabular}

During the experiment, the temperatures were measured at the inlet and outlet of the primary and secondary circuits of the heat exchanger as well as the water flow through the fibres. The measured data was to define the overall heat transfer coefficient $k\left(\mathrm{~W} \cdot \mathrm{m}^{-2} \cdot \mathrm{K}^{-1}\right)$ in accordance with Eq. (2):

$$
k=\frac{P}{S \cdot \Delta T_{\mathrm{ln}}},
$$

where $S$ is the total heat exchanger area of the bundle of fibres $\left[\mathrm{m}^{2}\right], P$ is the heat transfer rate of the exchanger [W] and $\Delta T_{\mathrm{ln}}$ is the logarithmic mean temperature difference (LMTD) [K].

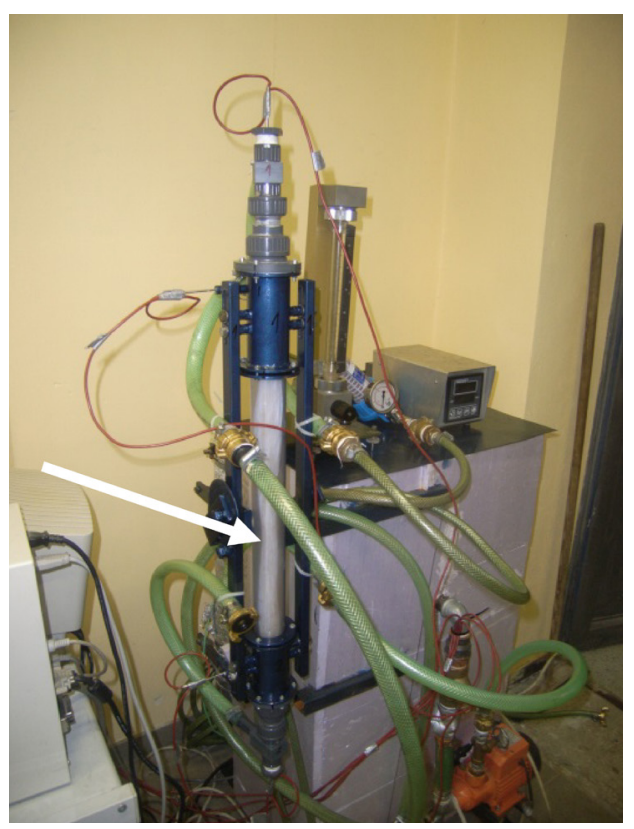

Fig. 10. Heat exchanger with tangential inlet and sliding head

The heat exchanger's performance is determined from the heated water in the secondary branch, i.e. in fibres. This medium herein is indicated with an index 2. Eq. (3) is valid:

$$
P=Q_{m 2} \cdot c_{p} \cdot\left(T_{2}^{\prime \prime}-T_{2}^{\prime}\right)
$$

The mean temperature logarithmic gradient is calculated from the Eq. (4):

$$
\Delta T_{\ln }=\frac{\Delta T_{0}-\Delta T_{S}}{\ln \frac{\Delta T_{0}}{\Delta T_{S}}} .
$$

At the counterflow heat exchanger, the individual differences of temperatures are determined from the Eqs. (5) and (6):

$$
\begin{aligned}
& \Delta T_{0}=T_{1}^{\prime}-T_{2}^{\prime \prime}, \\
& \Delta T_{S}=T_{1}^{\prime \prime}-T_{2}^{\prime},
\end{aligned}
$$

where index 1 is the primary medium; one bar represents the incoming temperature and two bars the outgoing temperature of the medium $[\mathrm{K}]$. 


\section{DISCUSSION}

Bundle type A was characterized by a large outer diameter of fibres $(0.65 \mathrm{~mm})$ and the fibres were relatively solid. When released by $0.7 \%$, the fibres were evenly deployed over the cross section and they were washed thoroughly. When released by $1.4 \%$, the fibres already touched the wall of the heat exchanger, which resulted in a decrease in the overall heat transfer coefficient. The course of the factor $k$ according to the flow rate of the fibre bundle (bundle A) is shown in Fig. 11.

The course of the heat transfer coefficient for bundle B is shown in Fig. 12 and for bundle C in Fig. 13.

In all three bundle types, the smallest overall heat transfer coefficient values were obtained at $0 \%$ release.

In a larger flow cross-section of fibres, higher overall heat transfer coefficients are reached when releasing a bundle up to circa $1 \%$. In smaller flow cross-sections of fibres, a greater release is more suitable (over $3 \%$ ). For example, with a flow of $100 \mathrm{dm}^{3} \cdot \mathrm{h}^{-1}$ and approximately the same bundle release ( $1.4 \%$ to $1.5 \%)$, a greater overall heat transfer coefficient value is shown by a B-type bundle (circa $590 \mathrm{~W} \cdot \mathrm{m}^{-2} \cdot \mathrm{K}^{-1}$ ). With the same flow, bundles A and C reach value $k$ of circa $420 \mathrm{~W} \cdot \mathrm{m}^{-2} \cdot \mathrm{K}^{-1}$.

In terms of evaluating the influence of measurement inaccuracies upon the results obtained, the following can be stated. The measured values included temperature, flow and pressure. The instruments that were used for measuring the stated values caused a so-called primary inaccuracy. A secondary inaccuracy resulted from the measurement of individual values of the given parameters due to the instruments used. A so-called tertiary inaccuracy should show what influence a particular parameter has upon the calculated value, i.e. upon overall heat transfer coefficient $k$.

If, in Eq. (2), we take into account the Eqs. (3) and (4), for overall heat transfer coefficient $k$ we obtain an equation in the shape:

$$
k=\frac{Q_{m 2} \cdot c_{p} \cdot\left(T_{2}^{\prime \prime}-T_{2}^{\prime}\right)}{S \cdot\left[\left(T_{1}^{\prime}-T_{2}^{\prime \prime}\right)-\left(T_{1}^{\prime \prime}-T_{2}^{\prime}\right)\right]} \cdot \ln \frac{\left(T_{1}^{\prime}-T_{2}^{\prime \prime}\right)}{\left(T_{1}^{\prime \prime}-T_{2}^{\prime}\right)} .
$$

The equation shows that the $k$ value is influenced by an inaccuracy in measuring temperature and flow.

The development of a percentage deviation (error) in the final value of overall heat transfer coefficient $k$ depend on the measurement error of the given parameters (each individually) is shown in

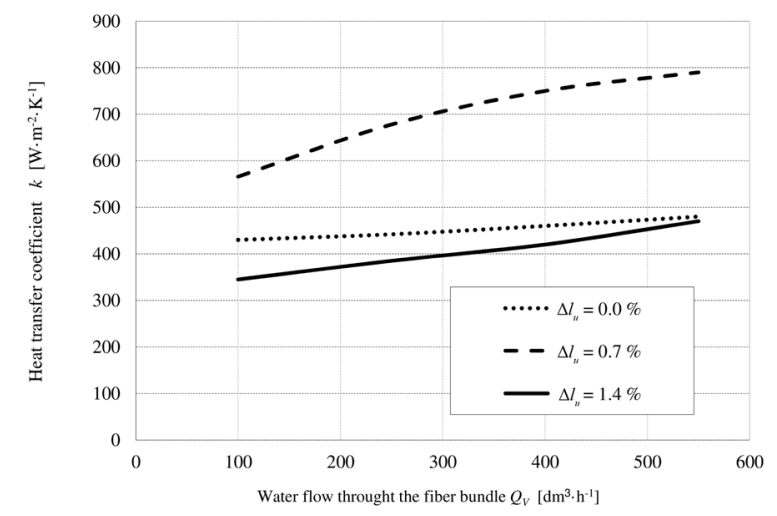

Fig. 11. Overall heat transfer coefficient for bundle type $A$

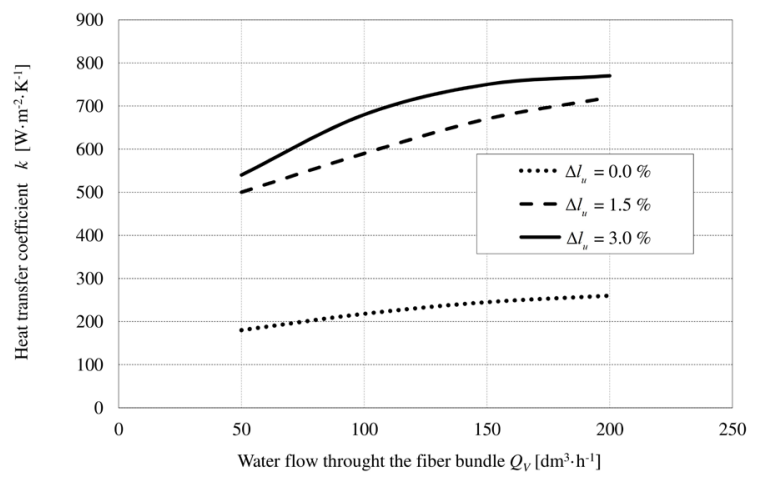

Fig. 12. Overall heat transfer coefficient for bundle type $B$

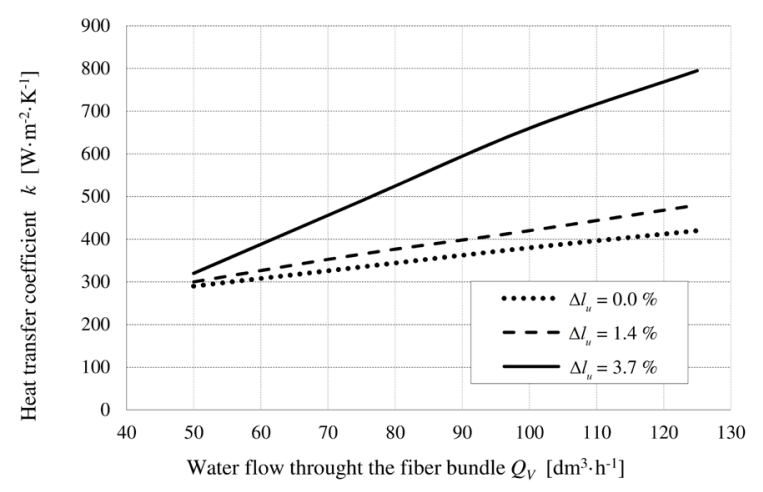

Fig. 13. Overall heat transfer coefficient for the bundle type $C$

Fig. 14 on the vertical axis. The horizontal axis shows the measurement error for the appropriate temperature and flow. The diagram shows a strong dependence of the overall heat transfer coefficient $k$ upon the temperature of outlet water from the exchanger $T_{2}^{\prime \prime}$ and flow $Q_{m 2}$ and relatively weaker dependence upon temperatures $T_{1}^{\prime}, T_{1}^{\prime \prime}$ and $T_{2}^{\prime}$.

In order to achieve the required accuracy when determining the overall heat transfer coefficient at a level of $3 \%$, thermal sensors with an accuracy of 


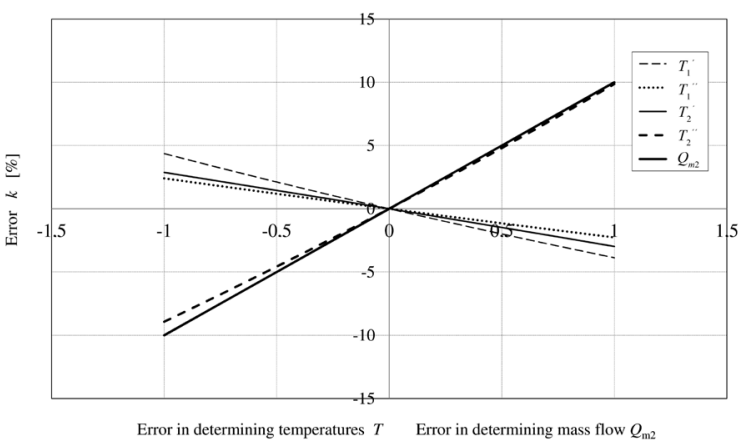

Fig. 14. The influence of inaccuracies in measured values upon the heat transfer coefficient

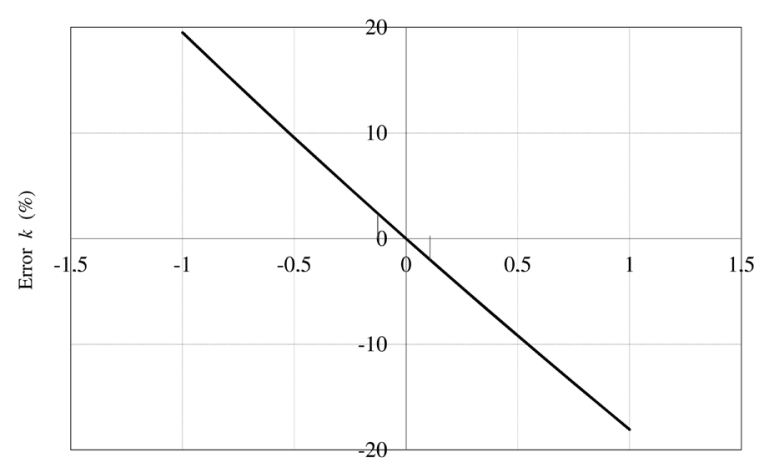

Error in determining temperatures $T_{1}{ }^{\prime}, T_{1}{ }^{\prime \prime}, T_{2}{ }^{\prime}, T_{2}{ }^{\prime \prime}$

Fig. 15. Overall heat transfer coefficient error depending upon the measured temperature

$\pm 0.1{ }^{\circ} \mathrm{C}$ must be used. This can be seen in Fig. 15 where there is a visible influence of deviations of the red values of all temperatures upon the $\mathrm{k}$ value. For example, if temperature $T_{2}^{\prime \prime}$ were read with an inaccuracy of $+0.5^{\circ} \mathrm{C}$ and other temperatures with an inaccuracy of $-0.5^{\circ} \mathrm{C}$, the resulting deviation in the overall heat transfer coefficient $\mathrm{k}$ would be as much as $\pm 10 \%$.

\section{CONCLUSIONS}

Examination of the heat exchangers made of polypropylene fibres showed that one of the fundamental problems in their application is the tightness of fibres in the potting. It has been established that at a water temperature above $52^{\circ} \mathrm{C}$, it is very difficult to ensure a leak-proof performance of the exchanger.

It is clear from the above that heat exchangers made of polypropylene fibres may only achieve faultless operation up to $50{ }^{\circ} \mathrm{C}$. Above this temperature, a breakdown in potting occurs, since it consists of three varying materials (metal, adhesive, polypropylene) whose change in shape depending upon temperature is expressed in different ways (each material has different thermal conductivity).

At the same time, measurements confirmed that a heat exchanger using fibres of a certain degree of release have a better performance in comparison to a design where fibres are under tension. To a certain degree, this result is related to the slight movement of the fibres along the cross-section which, at a certain release of fibre tension, causes a more intensive exchange of heat between the primary and secondary medium.

Testing the tightness of pottings took place at a pressure of $0.3 \mathrm{MPa}$. This pressure represents a sufficient reserve during application of the given exchangers in real operation when using low potential heat from waste water.

Finally, it is important to emphasize that the use of the heat exchangers of the polypropylene fibres is limited by the thermal, pressure, or strength resistance, respectively.

\section{ACKNOWLEDGEMENTS}

This paper was written with the financial support of Project VEGA No.1/0004/14 and SP2016/110-FMMI at Technical University of Ostrava.

\section{NOMENCLATURES}

$l_{\mathrm{z}}$ is the length of the bundle without tension, [m]

$\Delta l_{\mathrm{z}}$ the size of release, $[\mathrm{m}]$

$S$ the total heat exchange area of given fibre bundle, $\left[\mathrm{m}^{2}\right]$

$P$ heat transfer rate, [W]

$\Delta T_{\ln }$ logarithmic mean temperature difference, $[\mathrm{K}]$

$Q_{m 2}$ mass flow, [kg $\left.\cdot \mathrm{s}^{-1}\right]$

$c_{p}$ mean specific heat capacity, $\left[\mathrm{J} \cdot \mathrm{kg}^{-1} \cdot \mathrm{K}^{-1}\right]$

$T_{2}^{\prime}$ incoming water temperature, $[\mathrm{K}]$

$T_{2}^{\prime \prime}$ temperature of the exiting water, $[\mathrm{K}]$

$\Delta T_{0}$ temperature difference between the primary and the secondary medium at the beginning of the exchanger, [K]

$\Delta T_{S}$ similar difference but at the end of the exchanger, $[\mathrm{K}]$

\section{REFERENCES}

[1] Brestovič, T., Čarnogurská, M., Příhoda, M., Kubík, M. (2015). Simulation of heat transport at the cooling of the sugar solution in a recuperation exchanger. Acta Polytechnica, vol. 55, no. 3, p. 140-145. D0I:10.14311/AP.2015.55.0140. 
[2] Duransky, P., Papucik, S., Jandacka, J., Holubcik M., Nosek, R. (2014). Design of heat exchanger for Ericsson-Brayton piston engine. The Scientific World Journal, p. 1-6, Art. ID 138254, DOI:10.1155/2014/138254.

[3] Čarnogurská, M., Příhoda, M., Širillová, L.. (2014). Power losses and the efficiency of industrially used gearboxes. AIP Conference Proceedings, vol. 1608, p. 16-21, DOI:10.1063/1.4892699.

[4] Stritih, U., Bombač, A. (2014). Description and analysis of adsorption heat storage device. Strojniški vestnik - Journal of Mechanical Engineering, vol. 60, no. 10, p. 619-628. DOl:10.5545/sv-jme.2014.1814.

[5] Čarnogurská, M., Příhoda, M., Popčáková, D. (2010). Modelling the flow conditions in the tunnel and its reduced model. Journal of Mechanical Science and Technology, vol. 24, no. 12, p. 2479-2486, D0l:10.1007/s12206-010-0810-9.

[6] Honus, S., Němček, O, Juchelková, D. (2013). The analysis of the heat transfer into reactor walls in the thermal system and the verification. Advanced Materials Research, vols. 694697, p. 771-777, D0l:10.4028/www.scientific.net/AMR.694697.771.

[7] Příhoda, M., Rédr, M. (1998). Heat Transfer and Fluid Mechanics. VŠB-TU Ostrava, Ostrava. (in Czech)

[8] Vahidinia, F., Miri, M. (2015). Numerical study of the effect of the Reynolds numbers on thermal and hydrodynamic parameters of turbulent flow mixed convection heat transfer in an inclined tube. Strojniški vestnik - Journal of Mechanical Engineering. vol. 61, no. 11, p. 669-679, D0l:10.5545/svjme.2015.2818.

[9] Lienhard IV. J.H., Lienhard V. J.H. (2012). A Heat Transfer Textbook. 4th ed. Phlogiston Press, Cambridge.

[10] Jones, J.B., Hawkins, G.A. (1986). Engineering Thermodynamics, John Wiley, New York.

[11] Zaheed, L., Jachuck, R.J.J. (2004). Review of polymer compact heat exchangers, with special emphasis on a polymer film unit. Applied Thermal Engineering, vol. 24, no. 16, p. 23232358, D0I:10.1016/J.applthermaleng.2004.03.018.
[12] Zarkadas, D.M., Sirkar K.K. (2004). Polymeric hollow fiber heat exchangers: An alternative for lower temperature applications. Industrial \& Engineering Chemistry Research, vol. 43, no. 25, p. 8093-8106, DOl:10.1021/ie040143k.

[13] Raudensky, M., Dohnal, M. (2012). Large scale capillary based plastic heat exchangers. Chemical Engineering Transactions, vol. 29, p. 1477-1482, DOl:10.3303/CET1229247.

[14] Dohnal, M., Vesely, T., Raudensky, M. (2012). Low cost membrane contactors based on hollow fibres. EPJ Web of Conferences, vol. 25, p. 1-10, D0l:10.1051/ epjconf/20122501009.

[15] Raudensky, M., Dohnal, M. (2015). Fouling of polymeric hollow fiber heat exchanger by wastewater. Chemical Engineering Transactions, vol. 45, p. 949-951, D0I:10.3303/CET1545159.

[16] Pohl, S., Madzgalla, M., Manz, W., Bart, H.J. (2015). Biofouling on polymeric heat exchanger surfaces with $\mathrm{E}$. coli and native biofilms. The Journal of Bioadhesion and Biofilm Research, vol. 31, no. 9-10, p. 669-707, Dol:10.1080/08927014.2015. 1094691.

[17] Chen, Z.F. (2011). Application prospect of plastic heat exchanger in sewage source heat pump systems. International Conference on Management Science and Industrial Engineering, p. 1184-1187, Dol:10.1109/ MSIE.2011.5707631.

[18] Wicaksana, F., Fane, A.G., Chen, V. (2006). Fibre movement induced by bubbling using submerged hollow fibre membranes. Journal of Membrane Science, vol. 271, no. 1-2, p. 186-195, D0I:10.1016/j.memsci.2005.07.024.

[19] Oshman, Ch., Li, Q., Liew, L.A., Yang, R., Bright, V.M., Lee, Y.C. (2013). Flat flexible polymer heat pipes. Journal of Micromechanics and Microengineering, vol. 23, art. 015001, DOI:10.1088/0960-1317/23/1/015001.

[20] Astrouski, I., Raudensky, M., Dohnal, M. (2013). Particulate fouling of polymeric hollow fiber heat exchanger. International Conference on Heat Exchanger Fouling and Cleaning, Budapest, p. 233-239.

[21] Wikipedia (2015). from $h t t p: / / g 00 . g l / t q B o f N$ accessed on 2015-11-15. 